Sharif University of Technology
Scientia Iranica
SCIENTIA
I RAN I CA
http://scientiairanica.sharif.edu

\title{
Flood hazard risk evaluation using fuzzy logic and weightage-based combination methods in geographic information system
}

\author{
O. Sönmez* and H. Bizimana \\ Department of Civil Engineering, Sakarya University, 54187 Sakarya, Turkey.
}

Received 3 January 2016; received in revised form 3 July 2017; accepted 22 September 2018

KEYWORDS
Flood;
Weights;
Zoning;
Multi-criteria
environment;
Geographic
Information System
(GIS);
Fuzzy logic;
Weighted linear
combination.

\section{KEYWORDS}

Multi-criteria

environment;

Geographic

Information System

(GIS);

Weighted linear

combination.

\begin{abstract}
This study addresses the crucial variables that contribute highly to the risk of flood based on the flood characteristics of the Waverly region and develops a fuzzy logic and geographic information-based urban flood map with flood zones in Waverly City, Iowa. The methodology emphasizes weighting crucial variables using spatial analyst tools and fuzzy logic-based Geographic Information System (GIS) mapping. Local elevation, distance from Cedar River, land use, and population density in Waverly City are recognized as effective variables involved in the risk of flood in Waverly City. Twenty-three calibration tests for determining the weights of these variables on the risk of flood were performed and compared to previously produced Waverly flood risk maps. Finally, the weights of these variables were assigned as $70 \%$ for elevation, $20 \%$ for distance from Cedar River, $5 \%$ for Manning's coefficient, and $5 \%$ for population density. In a fuzzy environment, they were assigned to different fuzzy membership functions: For elevation, fuzzification technique small was used; for distance, fuzzification technique MS small was used; for Manning's coefficient and population density, fuzzification technique large was used. The flood hazard maps created were overlaid with 100- and 500-year flood maps of Waverly City for calibration and risk evaluation.

(C) 2020 Sharif University of Technology. All rights reserved.
\end{abstract}

\section{Introduction}

Over the last few years, among natural disasters, flood has been found to be among the most prevalent and destructive disasters in human civilization and has affected almost half of all people negatively with natural hazards. In ten years prior to 2011, the economic loss resulting from a number of flood incidents was estimated to reach US $\$ 185$ billion; nearly $31 \%$ of economic losses caused by natural hazard events

*. Corresponding author. Tel.: +905512134948 E-mail addresses: osonmez@sakarya.edu.tr (O. Sönmez); bizhu\%@yahoo.fr (H. Bizimana)

doi: $10.24200 /$ sci. 2018.21037 account for flood disaster scenario. Technically, flood occurs when, at a given time, normal dry land that does not contain water or is not under planned inundation areas is covered by water in a very short or short amount of time [1]. Nearly $20 \%$ of the population in the world stay in coastal areas home to the highest population density and are subjected to the high risk of flood most of the time. Developing countries, especially those located in regions with monsoon climate, are most frequently subjected to river flooding. As the actual climate change rages around the globe, an increase in soil moisture, deforestation to a high level, a high increase in urbanization, open river channel, and many floodplain modifications are actually identified as the very determining reasons around the globe that make flooding more intensive, destructive, and 
frequent [2]. Environmental system, social life, and numerous economic aspects found in the human society are definitely affected directly or/and indirectly by floods. In addition, more and more people in the future will be involved in dealing with floods due to increasing urbanization [3].

Due to the flooding increase, its destructive impact, and a rapid increase in urbanization, it is necessary and very important to improve the process of identifying, localizing, and mapping the flood hazard. Urban flooding maps can be used as robust, supporting and appropriate tools for city and regional planning systems, city expansion, and their growth management. This study aims to present the most probable model for an urban flood hazard and risk with WLC-based and fuzzy logic-based techniques and to calibrate produced models with 100- and 500-year flood maps of Waverly City using certain weights to obtain the best expected flood risk maps. The study is done in an urban area of the city of Waverly in Iowa in the North-East of USA and demonstrates a combination of natural factors and those resulting from human activities responsible for increasing the risk of flood hazard. As previously mentioned, in this study, multi-criteria-based weights in a linear combination methodology applied in ARCMAP of Geographic Information System (GIS) 10.2 combined with fuzzy logic membership functions are used to produce a flood risk model.

Linear combination with weightages technique can be considered as a way for quick and most complex decision-making in most complex maps found in GIS. Linear combination with weightages or simply addable weighting technique is formed based on the idea of average weights. Following this idea, continuous criteria have also been numerically calibrated. The weight assigned to every criterion can directly be allocated or reallocated based on the level of its importance. Eq. (1) elaborates the function as follows:

$$
S=\sigma W_{i} X_{i},
$$

where $S$ is the flood index, $W_{i}$ is the weight of added criterion equal to $1, X_{i}$ is the value of each factor that is found in the criterion's standardized score, and $i$ is the number of criteria [4]. Each input found is used in a formatted raster with a cell size of $(21 \mathrm{~m} \times 21 \mathrm{~m})$. In this study, the given flood indicators are combined to create the most probable flood map for Waverly City.

Fuzzy logic technique was invented in 1965 and is nowadays seen as a powerful tool that deals with uncertainties and related phenomena in a vague environment. Fuzzy logic also helps solve scenarios in incomplete, inexact or not totally reliable environment, because fuzzy logic deals with uncertainty and mostly approximation instead of exactness. Natural disasters also are highly accompanied by vagueness; with the climate changes, the inexactness of what maybe the cause of a given natural disaster on a global scale is increasing [5].

\subsection{Variables and factors of flood occurrence and their impacts}

In this research, a robust and intensive reading of different literatures of almost similar works [5] was conducted, and the current researcher assessed all possible factors in similar research studies to identify and define appropriate variables to define the most probable flood maps. The following variables are selected based on the physical characteristics of the region and the data available. The distance from the main stream or river affects flooding in a way that regions located near the water sources, such as streams and rivers, are highly subjected to the high risk of flooding. Water overflow occurring during the flood incident negatively affects the regions adjacent to the water source, and they are frequently vulnerable to and influenced by flooding [6]. Further, elevation affects flooding by evaluating the topography, and physical characteristics found in any environment must be considered with respect to its risk exposure to hazard vulnerability in the environment. Topography affects the severity of the flood, flow size, and volume and its direction [6]. Normally, a region with low elevation is affected by flood more than a region with high elevation or land. Moreover, it is seen that water remains in the lower regions or places for relatively a longer period of time when compared to the higher regions or places [7]. Low region is defined as the most vulnerable region at the time of flooding following the occurrence of a quick inundation. In addition, mostly, because of water gravity, water is pulled towards low regions that makes the flood impact highly significant [7]. The land use and land cover affect flooding by decreasing the infiltrated water and increasing runoff. Infiltration capacity is very different from a type of land use to another type of land use category. By considering the total given level, water bodies can intercept or retain much of runoff water. Therefore, it is seen that the impervious covered surfaces, which cover most parties of urbanized region, are defined to have the lowest infiltration or water absorption capacity. In this regard, it suffices to mention that flood events conversely relate to the present type of vegetation and its density. Vegetation cover and existing green places protect the land cover by simultaneously bringing into control and slowing down runoff and water overflow speed and not scouring velocity by reducing flow kinematic energy [7]. Therefore, urbanized areas with many impermeable covered surfaces and lack of vegetation and green spaces cannot be enough to handle flow velocity and water stagnation followed by the increase of peak discharge, leading to flash floods and the whole region highly influenced by floods $[8,9]$. When evaluating 
flood risk, which is the flood hazard caused by a given flood that occurs and is followed by its possible damage to the affected area, it is at first imperative to study life losses with respect to the population density; population density is found to provide information that helps recognize the area with a higher concentration of the population. It can be concluded that an area with higher population density including the higher number of people and infrastructure is likely to be affected by the flood as mentioned by Itami and Cotter [10], Tao and Jingdong [11].

\subsection{Fuzzy membership types and weightage technique}

Basically, in this research, four variables have been chosen among significant factors, which are the most contributing factors in the risk of flooding within Waverly City. Following each variable's contribution to the risk, each variable is divided into sub variables, too. In order to reclassify the variable, each sub-variable must be ranked based on literature review and experts' opinion to specify the level of importance regarding flooding [11].

Tao and Jingdong [11] showed that fuzzy membership type should be set for each criterion to assign the level of risk and find the right layout and that fuzzy memberships should be selected based on the data characteristic and mostly the way that data contribute to the risk of flooding. This study uses three types of fuzzy membership including fuzzy MS small, fuzzy small, and fuzzy large to produce the fuzzy data layer. Fuzzy MS small is used when a very small value in a given set of values is more likely to be part of the subset that affects a given event [12]. For example, the elevation layer dataset is defined within the range of 0 to $1000 \mathrm{~m}$, considering an area with an elevation below $5 \mathrm{~m}$ as the highest possibility in terms of flood occurrence. Therefore, the elevation layer is labeled and becomes standard by using fuzzy MS small function [13]. Fuzzy large is used when a larger value is more likely to be a member of the subset that affects a given event, while fuzzy small is used when a smaller value is more likely to be part of the subset that affects a given event [14]. In fact, fuzzy large membership function can be used to set the slope level of impact (in terms of angle) and population density layers where the higher the data are, the higher the risk will be [15]. It is found that other layers, especially those with distance from river or discharge channels, are arranged by using the fuzzy small function if the distance in question is not that large; however, if the distance is large, fuzzy MS small will be used [16]. The application of fuzzy membership functions as a modeling methodology provides a way to classify the given data in the range between 0 and 1 regarding the level of membership. For example, values assigned by 0 do not have any possibility for flood occurrence at all, while the value of 1 defines the locations with the highest possibility of flooding [17]. Finally, weights are assigned to each variable based on its implication level in flooding. Table 3 indicates variables, subvariables, and assigned rank for reclassification and, also, indicates fuzzy membership function types used with associated weightage values that are used to create the most probable flood map in an ArcGIS 10.0 environment.

\section{Material and methods}

\subsection{Weighted linear combination modeling of flood risk}

A data analysis processing-based method is used here while taking into consideration the application of reclassify tool and weighted overlay of the spatial analyst tool in ArcGIS 10.2. Geographical data include elevation, distance, and land cover, considering the Manning's coefficient as the indicator of the type of land cover and population derived from given settlements' data.

In order to make sure that the study is trustworthy, several literature reviews have been used to determine which factor contributes the most to flooding in Waverly City and its management; hence, based on elevation from the Cedar River that passes through the city center, distance from the same Cedar River, land cover in different locations of the city, and the settlements presence and their density, a weighted linear modal using Arc map spatial analyst tools such as classify, reclassify, conversion, and weighted overlay is used to produce flood susceptibility maps. Finally, the flood susceptibility map found is in agreement with the inundation maps specific to 100-year and 500-year flood records of the study area previously produced by the University of Iowa, Hydraulics Department. There are no flood protection structures on shores of Cedar River, leaving the area next to the river fully unprotected and susceptible to flood. Figure 1 shows the methodology framework used in this study.

Following the classification of the flood causing factors, geographical information system is used to analyze the data and produce a flood susceptible map of Waverly City following twenty-three calibration tests to find the most compatible weightage combination of the used factors (for more details, see Table 1). The best results are selected by the map overlay methodology based on the best map resemblance when compared to maps produced based on discharge data shown in Figure 2 and the flood maps in Figure 3. All data used were derived from Iowa Department of Natural Resources, and 100-year and 500-year flood maps were taken from Iowa state wide flood mapping project (Figure 3) of 2012 [18,19]. All Geo data were obtained 


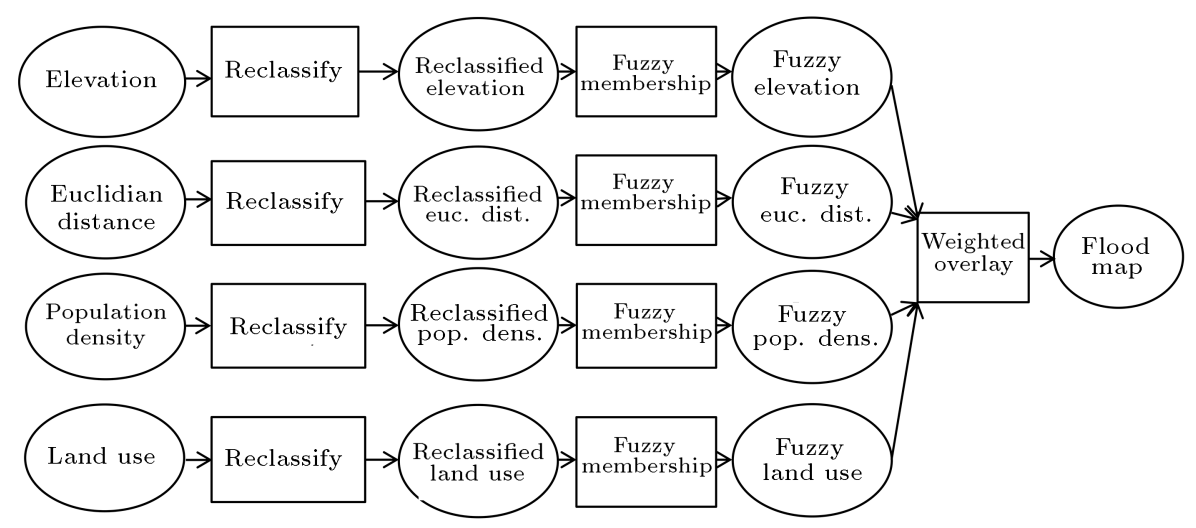

Figure 1. Methodology framework.

Table 1. Weight combination and calibration tests.

\begin{tabular}{|c|c|c|c|c|c|}
\hline $\begin{array}{c}\text { Weight } \\
\text { combinations }\end{array}$ & Elevation & $\begin{array}{l}\text { Euclidian } \\
\text { distance }\end{array}$ & $\begin{array}{l}\text { Land } \\
\text { cover }\end{array}$ & $\begin{array}{c}\text { Population } \\
\text { density }\end{array}$ & Test results \\
\hline 1 & 50 & 30 & 10 & 10 & Incompatible \\
\hline 2 & 40 & 50 & 5 & 5 & Incompatible \\
\hline 3 & 40 & 40 & 15 & 5 & Incompatible \\
\hline 4 & 30 & 60 & 5 & 5 & Incompatible \\
\hline 5 & 35 & 35 & 20 & 10 & Incompatible \\
\hline 6 & 60 & 30 & 5 & 5 & Incompatible \\
\hline 7 & 25 & 25 & 25 & 25 & Incompatible \\
\hline 8 & 35 & 35 & 10 & 20 & Incompatible \\
\hline 9 & 65 & 25 & 5 & 5 & Incompatible \\
\hline 10 & 55 & 25 & 15 & 5 & Incompatible \\
\hline 11 & 50 & 20 & 15 & 15 & Incompatible \\
\hline 12 & 70 & 15 & 5 & 10 & Less compatible \\
\hline 13 & 70 & 15 & 10 & 5 & Less compatible \\
\hline $14 *$ & 70 & 20 & 5 & 5 & Compatible \\
\hline 15 & 70 & 10 & 10 & 10 & Less compatible \\
\hline 16 & 80 & 10 & 5 & 5 & Less compatible \\
\hline 17 & 20 & 70 & 5 & 5 & Incompatible \\
\hline 18 & 65 & 35 & 0 & 0 & Incompatible \\
\hline 19 & 40 & 30 & 5 & 15 & Incompatible \\
\hline 20 & 35 & 40 & 15 & 10 & Incompatible \\
\hline 21 & 50 & 10 & 20 & 20 & Incompatible \\
\hline 22 & 20 & 50 & 10 & 20 & Incompatible \\
\hline 23 & 30 & 50 & 15 & 5 & Incompatible \\
\hline
\end{tabular}

*The best parameters combination that yielded the best model outcome.

on a scale of 1:24,000. Digital Elevation Modal (DEM) raster of Waverly City's terrain was used to give the elevation; an Euclidean distance was calculated from the DEM of Cedar River for a maximum distance of one thousand meters from Cedar River; a raster map showing the Manning's coefficient of the Waverly land cover materials was used to assess the land use, and a vector population map was produced from the settlement vector map and converted into a population raster map by using the conversion tool in Arc map. By applying reclassify tool of the GIS spatial analyst tool, classified maps of the elevation, Euclidian distance from Cedar River, land use, and population are produced with risk levels shown on every factor map as 1 (very 


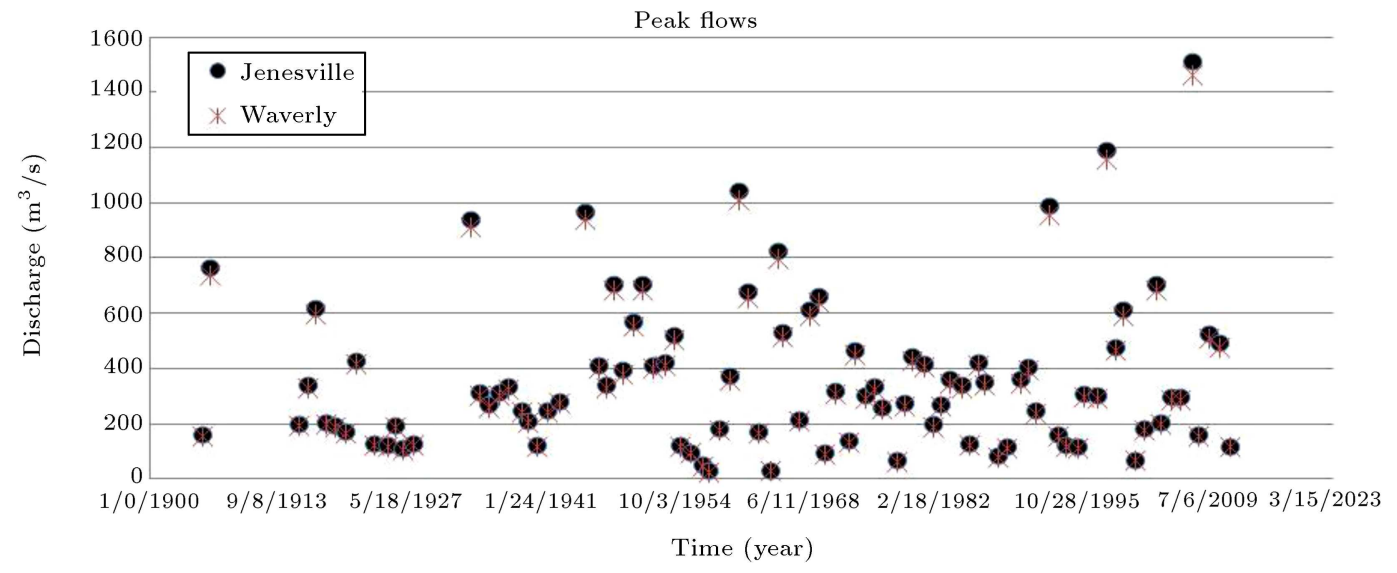

Figure 2. Artificial discharge of Waverly.

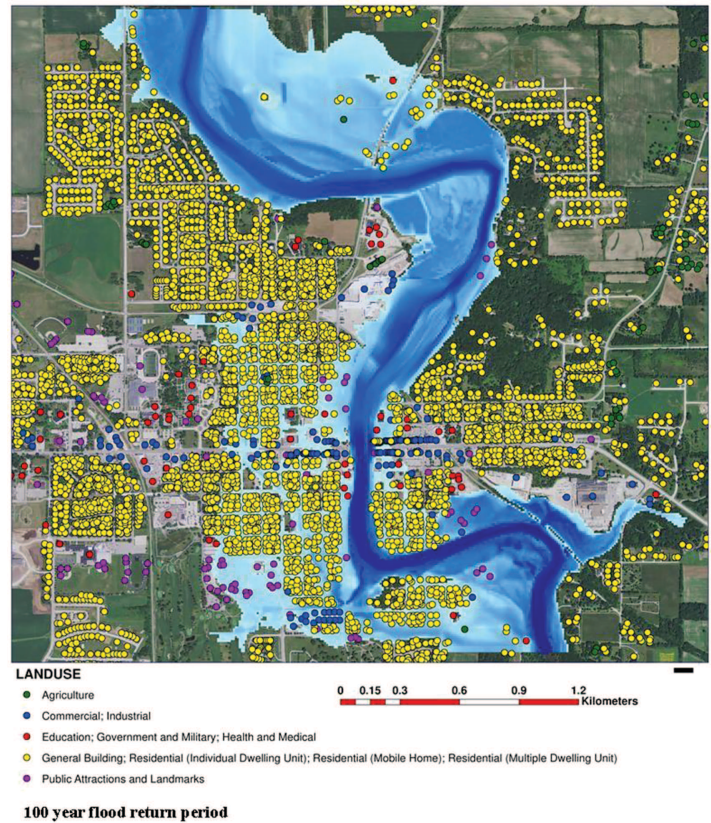

(a)

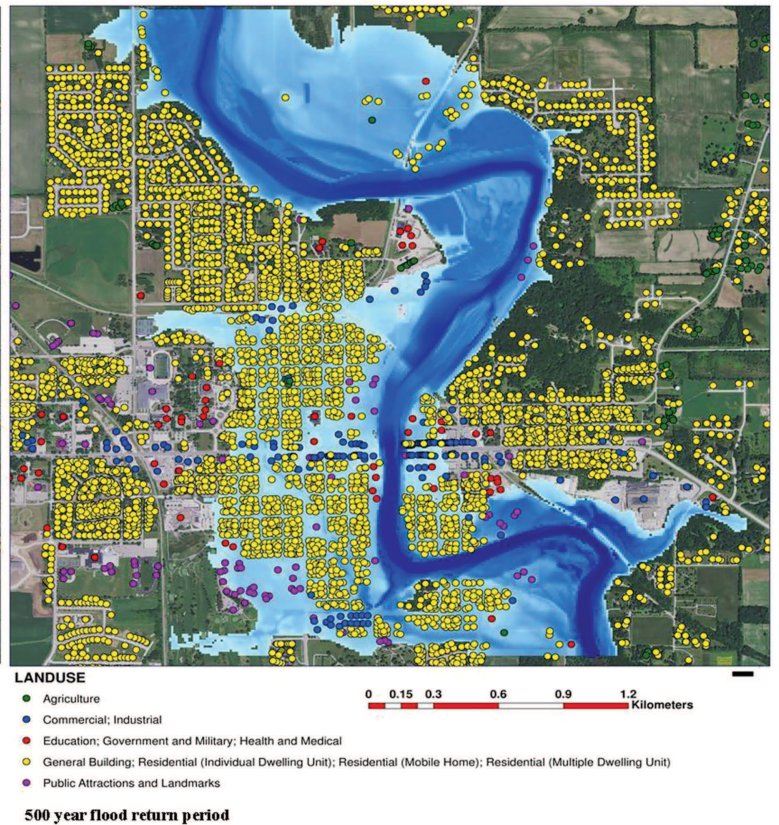

(b)

Figure 3. Overlaid maps of flood discharges for (a) 100-year and (b) 500-year return periods in Waverly.

high risk), 2 (high risk), 3 (medium risk), 4 (low risk), and 5 (very low risk).

\subsection{Fuzzy logic modeling of flood risk}

To develop fuzzy logic-based flood risk zones, crucial variables contributing to the occurrences of floods in any given region must be studied [19]. In this study, elevation found in Waverly City, distance from Cedar River, land use, and population density are used to assess the vulnerability level with respect to flooding of different locations in Waverly City, Iowa.

\subsubsection{Elevation}

If the elevation layer dataset is defined within the range of 0 to $1000 \mathrm{~m}$, e.g., considering an area of elevation below $5 \mathrm{~m}$ as the highest possibility in terms of flood occurrence, then the elevation layer is labeled and becomes standard by using fuzzy MS small function. In our case, the following are considered: an increase from a minimum elevation of $63 \mathrm{~m}$ at the river to $70 \mathrm{~m}$ upland; an increase from $63 \mathrm{~m}$ to $64 \mathrm{~m}$ from the Cedar River level as the most dangerous zone (Zone 1); an increase from $64 \mathrm{~m}$ to $65 \mathrm{~m}$ as the dangerous zone or Zone 2; an increase from $65 \mathrm{~m}$ to $66 \mathrm{~m}$ as a zone with average risk or Zone 3 ; an increase from $66 \mathrm{~m}$ to $68 \mathrm{~m}$ and $68 \mathrm{~m}$ to $70 \mathrm{~m}$ as Zones 4 and 5 , respectively, or a zone with low risk and very low risk of danger, respectively. In this case, we are using fuzzy small as a membership function because a small value is more likely to be part of the dataset. After conducting twenty-three calibration tests of weights combination and direct overlay of obtained result maps 
with respectively previous 100-year and 500-year flood hazard maps of Waverly City produced by the City of Waverly (Table 1), 18 test results were found to be incompatible with the previous 100-year and 500year flood hazard maps of Waverly City; four test results were less compatible, and only one test was found compatible with the elevation data set, which was considered to be the most influential factor in flooding in Waverly and with different weights given to elevation during calibration tests. Further to that, $70 \%$ of the weight proves higher compatibility with $100-$ and 500-year flood hazard maps from the city of Waverly (Table 1).

\subsubsection{Distance}

Distance from river or discharge channels is calculated by using the fuzzy small function if the distance in question is not that large; if the distance being evaluated is very large, fuzzy MS small will be used. In this study, a buffer zone of $1000 \mathrm{~m}$ from Cedar River with $0 \mathrm{~m}$ to $50 \mathrm{~m}$ is considered as a very dangerous zone or Zone 1; $50 \mathrm{~m}$ to $100 \mathrm{~m}$ as the dangerous zone or Zone 2; from $100 \mathrm{~m}$ to $250 \mathrm{~m}$ as average risk zone or Zone 3; from $250 \mathrm{~m}$ to $500 \mathrm{~m}, 500 \mathrm{~m}$ to $1000 \mathrm{~m}$ as a low-risk zone and a very low-risk zone, respectively, or Zones 4 and 5 . This distance requires the application of fuzzy MS small, because a place at $5 \mathrm{~m}$ from the river is far more susceptible to great danger than a place at $1000 \mathrm{~m}$. The best weight combination test results gave $20 \%$ of the weightage to the Euclidian distance (Table 1).

\subsubsection{Land use}

Land use distribution in Waverly City is complex. It ranges from water conveyance channels to constructions and parks. Manning's coefficient is used here, which indicates roughness and helps determine the capacity of a given land cover to allow or block water to/from infiltrate(ing) the soil, hence producing considerable runoff discharge or reducing it. Of note, any material with a low $n$ (Manning' coefficient) is likely to allow more rainfall water to turn into runoff, which reduces the infiltration considerably. For example, concrete and related material with high $n$ is likely to intercept the considerable amount of water, hence reducing the runoff, e.g., forests. Therefore, subclasses are formed following the Manning's roughness coefficient impacts on the flooding of Waverly City. To be specific, $38<=1 / n<=50$; this set is set to be the most dangerous one regarding the flood; the following sets including $33.1<=1 / n<38,22.1<=1 / n<33.1$, $9.8<=1 / n<22.1$, and $6.5<=1 / n<9.8$ are considered to be of high risk, medium risk, low, and very low risk, respectively, or $2,3,4$, and 5 . The fuzzy land use is calculated by using the fuzzy large function, because the larger the Manning's coefficient is, the more significant it becomes for flooding. The best weight combination test results gave $5 \%$ of the weightage to the land use (Table 1).

\subsubsection{Population}

Population distribution in Waverly City is also complex with many people residing in the city centre and closer to Cedar River and industrial areas, which make those people residing or working in an area at a close distance from the river likely to be negatively impacted by floods; subclasses aimed at assigning the level of negative impacts during a flood are formed, and the more populated places are the ones assigned to the zones with very high and high danger. A place inhabited by 8,835 to 10,716 people is set to be the most dangerous one regarding the flood's negative impacts; the following sets of 5,019 to $8,832,2,553$ to $5,016,1,797$ to 2,550 , and 1,290 to 1,794 are considered to be of high risk, medium risk, low, and very low risk, respectively, or $2,3,4$, and 5 . The fuzzy population is calculated by using the fuzzy large function, because the larger the population set is, the more they are negatively exposed to flood. The best weight combination test results gave $5 \%$ of the weightage to the population density (Table 1).

\subsection{Flow data of Waverly city}

United States Geological Survey (USGS) stream gage 05458300 is located at the bridge crossing at Horton Road. The drainage area at the USGS gage is 1547 square kilometers. Stage-discharge and peak discharges have been recorded continuously at the gage since 2001 . The largest flood on record occurred in 2008 with 1489.46 cubic meters per second value. However, the number of peak discharges is not enough for hydrological analysis. Therefore, historical peak discharges were calculated using "Area-Weighted Estimates for Ungaged Sites on Gaged Streams" methods. USGS stream gage 05458500-Jenesville is located $19.5 \mathrm{~km}$ downstream of USGS stream gage 05458300-Waverly. Figure 2 shows the peak flows in Waverly City recorded from 1905 to 2014. These discharge data are observed at Bremer County, IO, Hydrologic Unit 07080201, on the downstream side of the bridge in county Highway V14 at northern edge of Waverly [19].

Values of flood discharges were calculated using the artificial historical peak flows (Figure 2). The data compiled in the bulletin 17B of the USGS from the hydrology subcommittee of the USGS were chosen as a calculation method for flood discharges in HECSSP software (Table 2). Figure 3 presents the flood discharges of 100- and 500-year return periods of Waverly City, produced by USGS [19].

\section{Results and discussion}

Flood risk is defined as the flood hazard of a given 
Table 2. Flood discharges with 100- and 500-year return periods.

\begin{tabular}{cccc}
\hline $\begin{array}{c}\text { Return period } \\
\text { (year) }\end{array}$ & $\begin{array}{c}\text { Discharge } \\
\text { (cubic meter) }\end{array}$ & $\begin{array}{c}\text { 5\% confidence } \\
\text { limit }\end{array}$ & $\begin{array}{c}\mathbf{9 5 \%} \text { confidence } \\
\text { limit }\end{array}$ \\
\hline 500 & 1631.4 & 2447 & 1439 \\
100 & 1232.5 & 1746 & 1093 \\
\hline
\end{tabular}

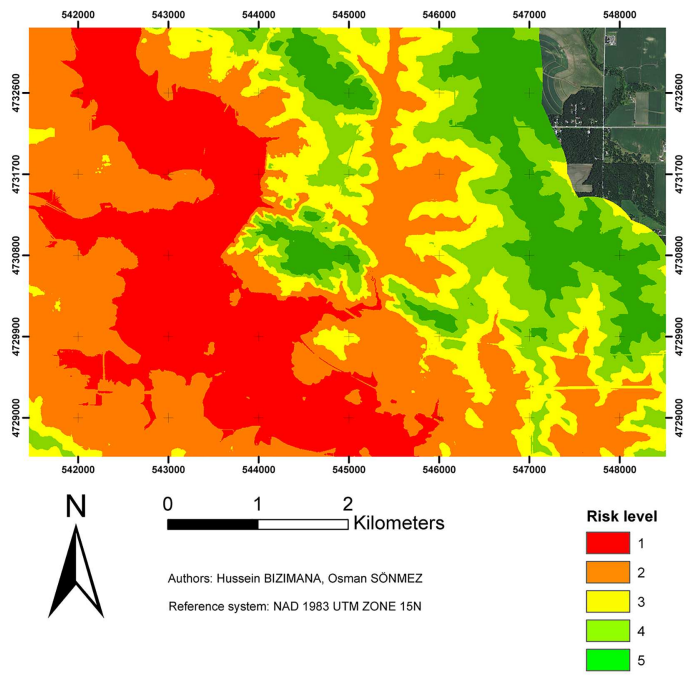

(a)

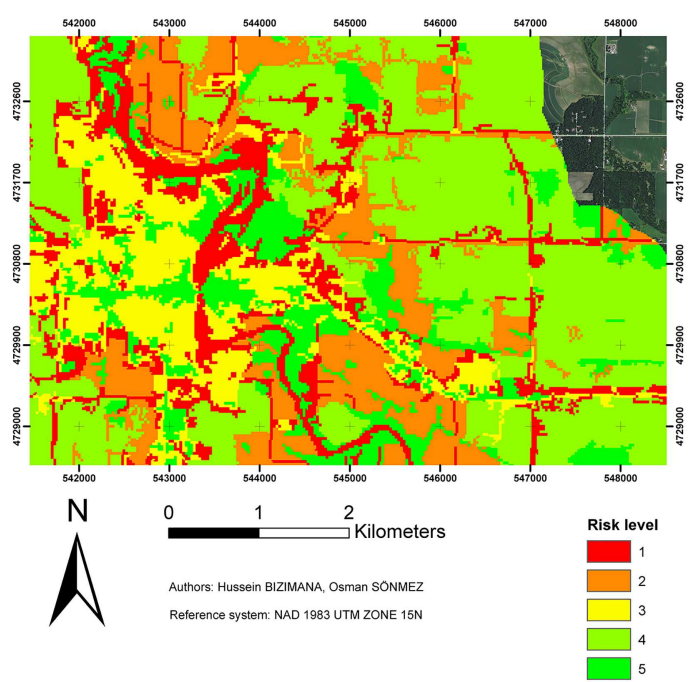

(c)

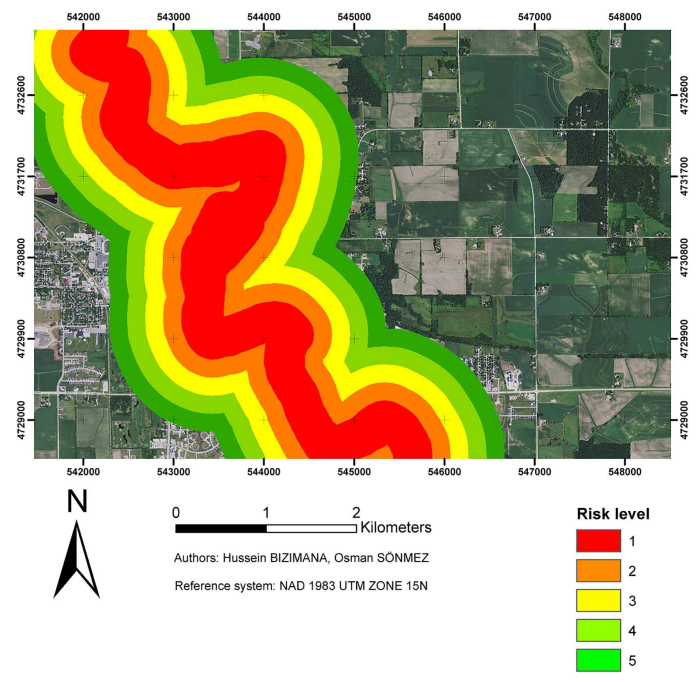

(b)

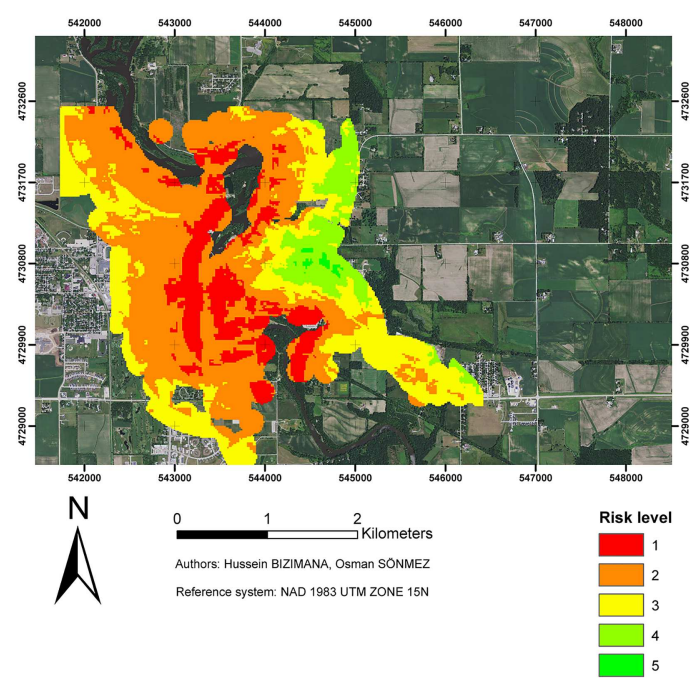

(d)

Figure 4. Reclassified maps for (a) elevation, (b) distance, (c) land use, and (d) population density in a Boolean GIS method.

flood event $(p)$ combined with the level of damages that are likely to be caused by the flood $(D)$; thus, Flood Risk (FR) equals flood event probability $(p)$ multiplied by caused damages $(D)$. Therefore, in this research, the application of fuzzy logic-based flood risk mapping shows that a given place at the shore of Cedar River is highly subjected to flood hazard as no flood protection structure is present; however, flood risk of that location might be lower than that of a place at 300 meters from the shower, where there are residential and commercial areas subjected to high flood damages. In this research study, two different flood hazard risk maps were produced by the application of two different tools.

The application of the conventional mapping technique and obtained results, shown in Figure 4, indicate 


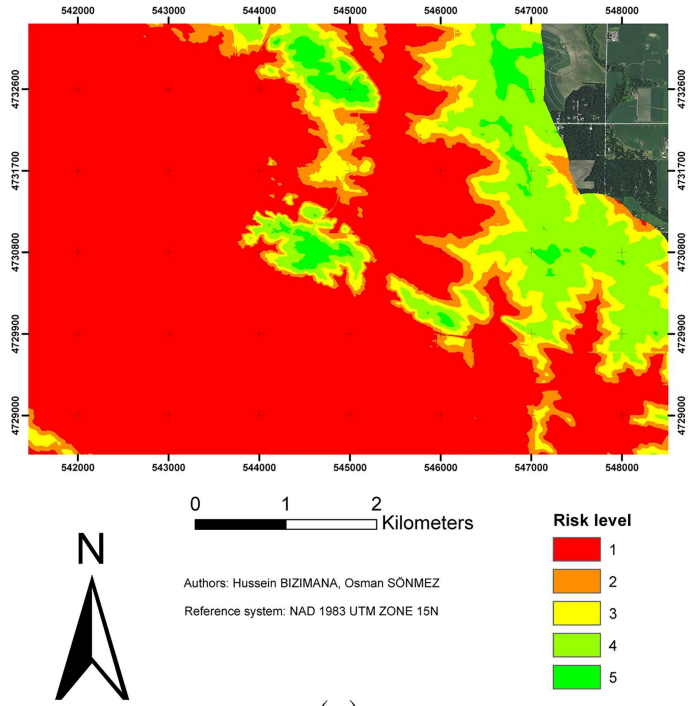

(a)

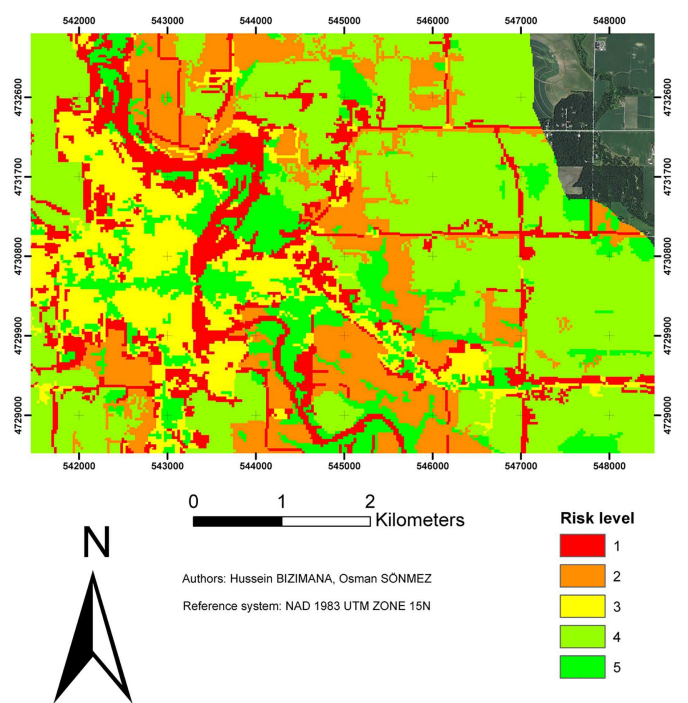

(c)

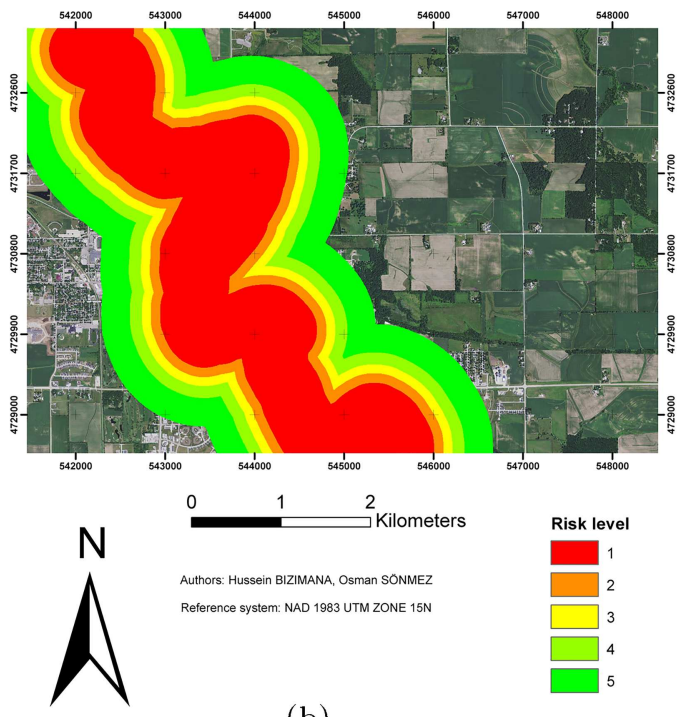

(b)

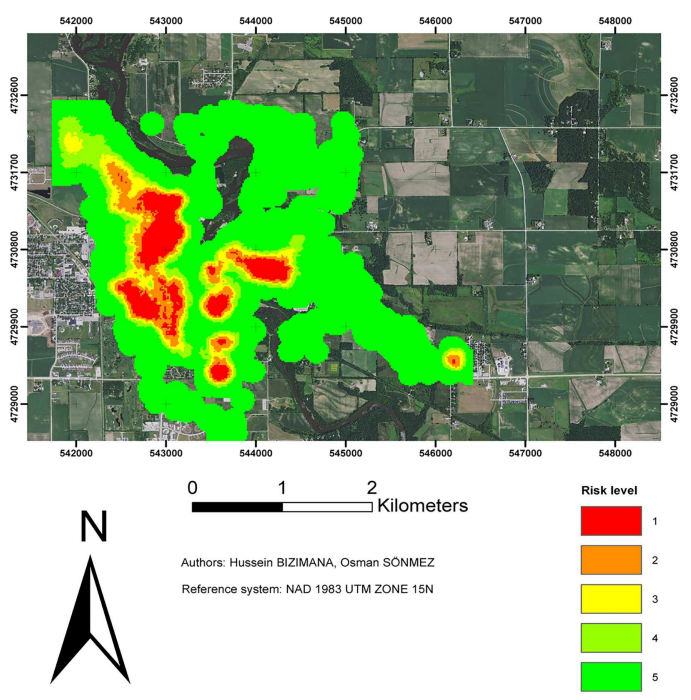

(d)

Figure 5. Reclassified maps for (a) elevation, (b) distance, (c) land use, and (d) population density in a fuzzy GIS method.

that four factors including elevation, distance, land use, and population density are subjected to a Booleanbased technique where a point is either part of a set or is not part of a set; therefore, the distance close to Cedar River is susceptible to the high risk of flooding and the distance not close to the river is safe, which means no flooding. However, by using the fuzzy logicbased GIS method shown in Figure 5, the results show that a point is either part of a set, not part of a set, or partially part of a set, meaning that to be close to the river is a wide set, which is of different membership degrees such as very close, averagely close, and close; hence, the flooding level in a given location is given by its membership degree to a given set of variables such as elevation, distance from the flood source (Cedar River in this case), land use, and population density.
Final results are shown in Figures 6, 7, and 8; results of a linear combination of weightages in GIS and a linear combination of weightage and a fuzzy logic membership functions shown in (Table 3 ) are presented. Maps presented in Figures 6, 7, and 8 all represent flood risk zones from low-risk to high-risk zones; the risk of flooding shows a decrease from Cedar River as the main source of flood is at the east of the river and spreads to the west of the river following its lower elevation compared to the East of Cedar River. Areas with very high and high risk of floods are found from Cedar River going up to Waverly Stadium, with the region of highest risk located close to Cedar River, plains, and a considerable density of people, business and economic activities-based infrastructures. Regions or areas with low probability of flooding such as low and 

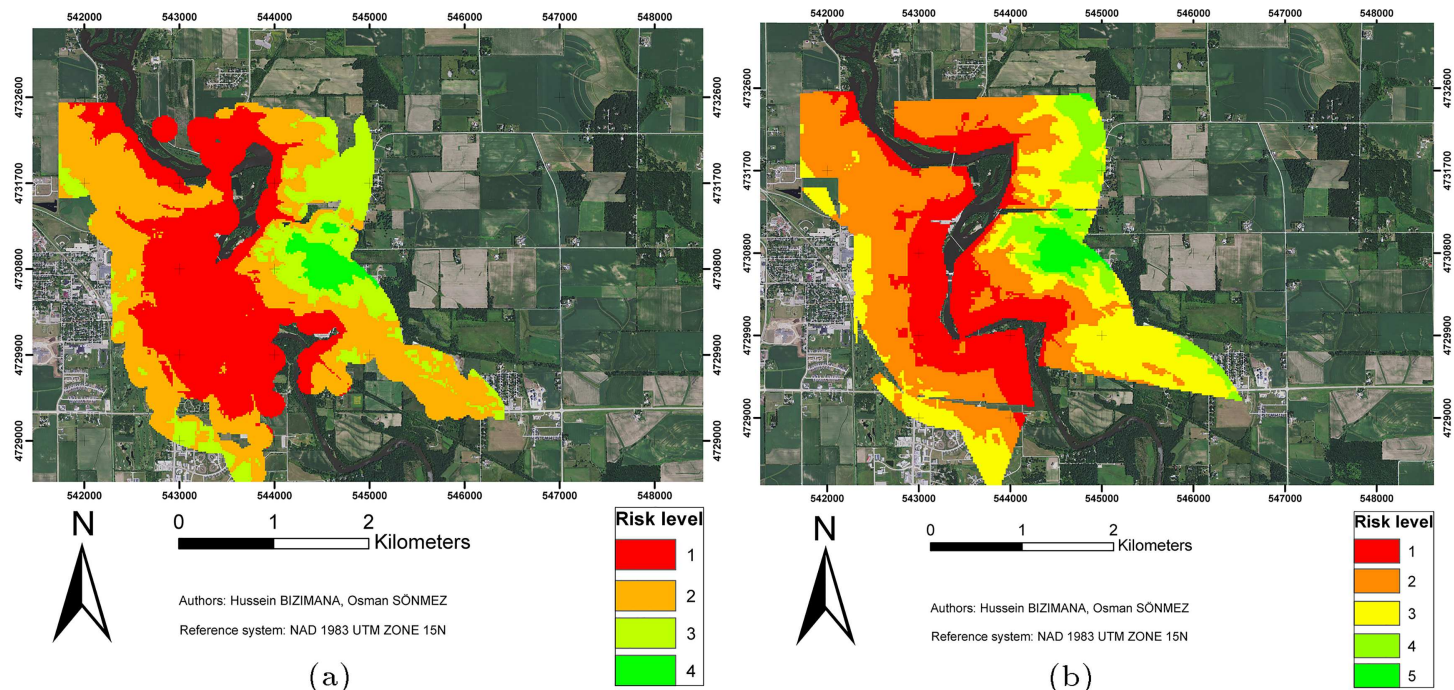

Figure 6. (a) Fuzzy-based and (b) WLC-based flood susceptible maps in Waverly City.
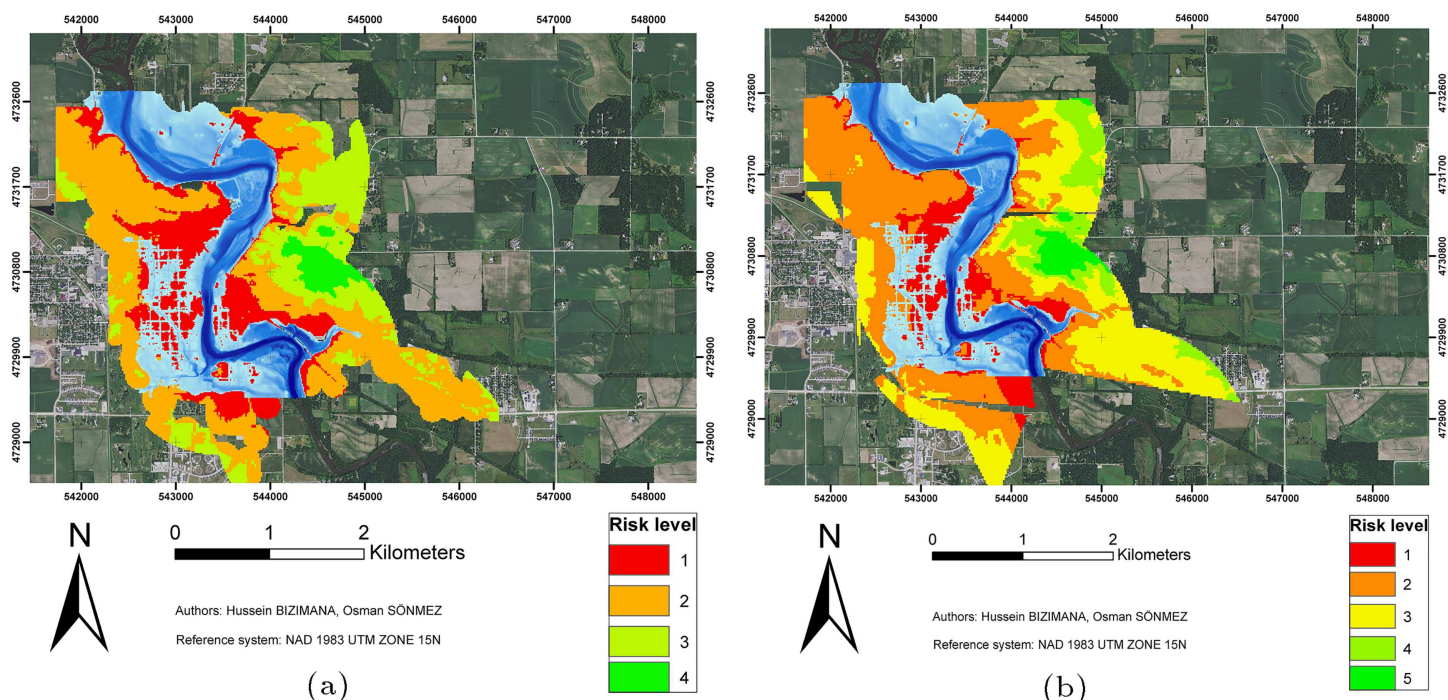

Figure 7. (a) Fuzzy and (b) WLC-based flood susceptible maps in Waverly City overlaid with 100-year return period flood (blue color).

very low risky zones are located at the east from Cedar River, with moderated high grounds and are inhabited by less people.

According to the United State Federal Emergency Agency, flood hazard zones are classified with respect to their proximity to flood source; an area with $1 \%$ or a higher chance of flooding is mentioned as a 100-year flood chance area. Some places are called special flood hazard areas and are classified as zones in the following way: A, AH, AO, A1 and A30, A99, AE and/or A1 to

Table 3. Used weightage ratios and fuzzy membership functions.

\begin{tabular}{|c|c|c|c|c|c|c|c|}
\hline Risk degree & Very high risk & High risk & Medium risk & Low risk & Very low risk & $\begin{array}{c}\text { Fuzzy } \\
\text { membership } \\
\text { functions }\end{array}$ & Weightage \\
\hline Risk potential & 1 & 2 & 3 & 4 & 5 & & \\
\hline Elevation & $63 \mathrm{~m}$ to $64 \mathrm{~m}$ & $64 \mathrm{~m}$ to $65 \mathrm{~m}$ & $65 \mathrm{~m}$ to $66 \mathrm{~m}$ & $66 \mathrm{~m}$ to $68 \mathrm{~m}$ & $68 \mathrm{~m}$ to $70 \mathrm{~m}$ & $\begin{array}{l}\text { Fuzzy } \\
\text { Small }\end{array}$ & $70 \%$ \\
\hline Distance & $>=50 \mathrm{~m}$ & $50<\mathrm{m}<=100$ & $100<\mathrm{m}<=250$ & $250<\mathrm{m}<=500$ & $500<\mathrm{m}<=1000$ & $\begin{array}{c}\text { Fuzzy } \\
\text { MS Small }\end{array}$ & $20 \%$ \\
\hline Land use & $38<=1 / n<=50$ & $33.1<=1 / n<38$ & $22.1<=1 / n<33.1$ & $9.8<=1 / n<22.1$ & $6.5<=1 / n<9.8$ & $\begin{array}{l}\text { Fuzzy } \\
\text { Large }\end{array}$ & $5 \%$ \\
\hline Population & 8,835 to 10,716 & 5,019 to 8,832 & 2,553 to 5,016 & 1,797 to 2,550 & 1,290 to 1,794 & $\begin{array}{l}\text { Fuzzy } \\
\text { Large }\end{array}$ & $5 \%$ \\
\hline
\end{tabular}




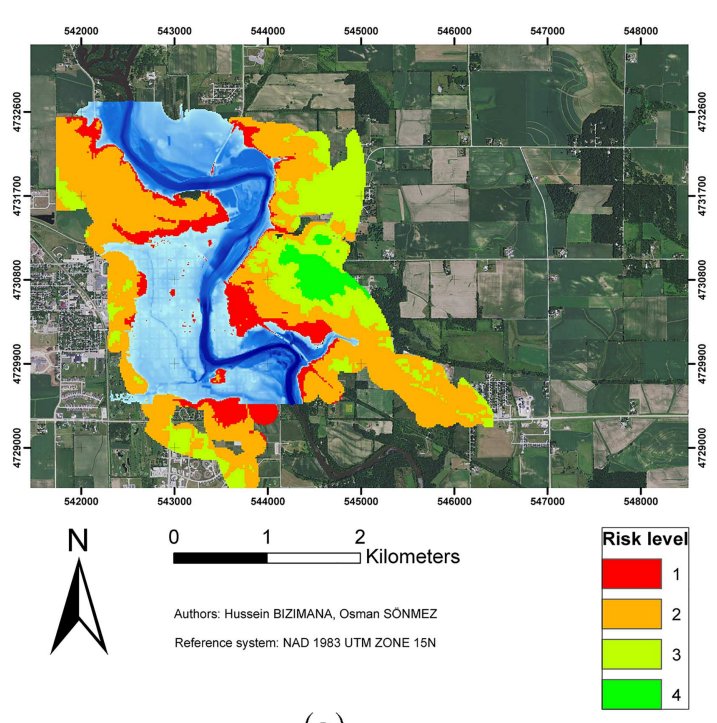

(a)

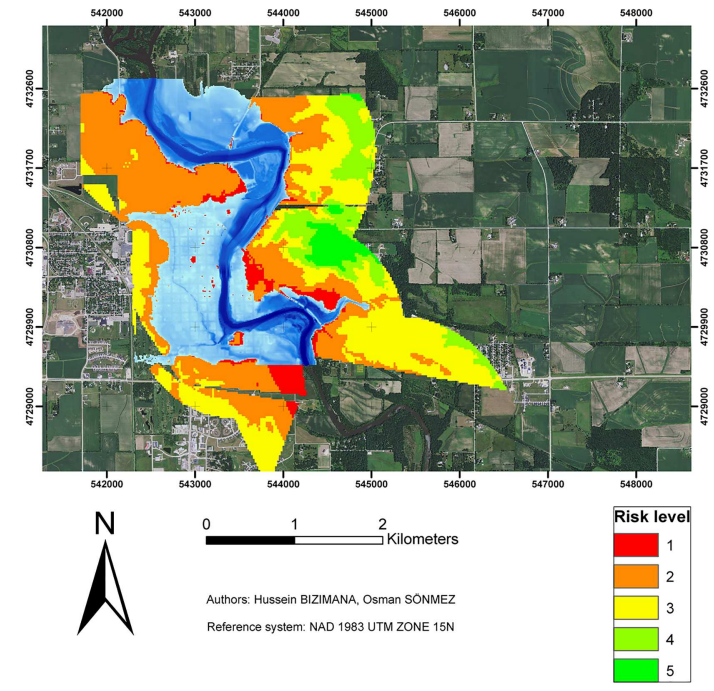

(b)

Figure 8. (a) Fuzzy-based and (b) WLC-based flood susceptible maps in Waverly City overlaid with 500-year return period flood (blue color).

Table 4. Flood level and risk potential of affected area and properties using fuzzy-based GIS methodology.

\begin{tabular}{lccccc}
\hline Risk level & Risk potential & $\begin{array}{c}\text { Affected area } \\
\left(\mathbf{k m}^{\mathbf{2}}\right)\end{array}$ & $\mathbf{\%}$ & Affected properties & \% \\
\hline High flood risk & 1 & 3.61 & 39.42 & 1896 & 51.32 \\
Average flood risk & 2 & 3.73 & 40.74 & 1354 & 36.65 \\
Low flood risk & $3 \& 4$ & 1.81 & 19.82 & 437 & 11.82 \\
& Total & 9.69 & 100 & 3694 & 100 \\
\hline
\end{tabular}

Table 5. Flood level and risk potential of affected area and properties with a weightage-based combination methodology.

\begin{tabular}{lccccc}
\hline Risk level & Risk potential & $\begin{array}{c}\text { Affected area } \\
\left(\mathbf{k m}^{\mathbf{2}}\right)\end{array}$ & $\mathbf{\%}$ & Affected properties & \% \\
\hline Very high risk & 1 & 2.36 & 24.35 & 1114 & 30.15 \\
High risk & 2 & 3.86 & 39.87 & 1820 & 49.26 \\
Average risk & 3 & 2.44 & 25.18 & 454 & 12.29 \\
Low risk & 4 & 0.76 & 7.88 & 161 & 4.35 \\
Very low risk & 5 & 0.26 & 2.70 & 115 & 3.11 \\
& Total & 9.69 & 100 & 3694 & 100 \\
\hline
\end{tabular}

A30; other zones are mentioned as AR or A, V, VE, and V1 to V30. The flood map produced indicates that all these areas are within a very high flood zone or Zone 1 , and high flood area or zone comprises $6.22 \mathrm{~km}^{2}$ of $9.68 \mathrm{~km}^{2}$, which is $64.25 \%$ of the study area (Tables 4 and 5). Averagely flooded areas are represented by $\mathrm{B}$ or $\mathrm{X}$ in FEMA flood classification [19]. The results of this study show that averagely flooded areas are represented in Zone 3 and are zones that can be affected by flood return periods between 100-year flood and 500-year flood. The areas under the lowest probability of floods are represented as X or C in FEMA flood scope and, in this study, they are represented in Zones 4 and 5 .
Zones 4 and 5 represent the areas under the probability of flooding by a 500-year return period.

\section{Conclusion}

This research on flood risk zoning used weighted linear combination and fuzzy logic-based overlaying in GIS. Calibration with previously modeled results of Waverly City flood maps (Figure 3) was performed in the calibration process; different weightages were given to the considered factors (as shown in Table 1). The aim of the calibration was to find the best possible combination of weightages that produces results of high 
similarity to the Waverly flood maps (Figure 3 ). The best combination during calibration was Calibration 14 (Table 1) and, by using this calibration, reliable flood risk maps of Waverly City were obtained (Figures 6, 7 , and 8). The comparison of fuzzy logic-based results and weight linear combination with a Boolean logicbased showed the convergence of results to those given by the hydraulic models shown previously in Figure 3, because fuzzy logic considered the membership degrees of every considered four factors while taking into consideration the rising uncertainty in the natural topography of Waverly City and combining very high risk and high risk levels found using WLC technique into one high-risk zone susceptible to floods. All point locations found in zones with low elevation and close distance from the river are labeled as high risk of flooding zone by fuzzy membership functions, and results are more in agreement with flood maps with return periods produced in Waverly City compared to the case where weighted overlay combination with Boolean classic logic is used. By using WLC method, the clear separation from very high risk to high risk is defined, and places very close to Cedar River with lower elevation are directly defined to be of very high risk, which might not consider some places under high risk of floods because of the existing population density and commercial areas. It was shown that very high risk and high flood risk zones covered $6.22 \mathrm{~km}^{2}$ of $9.69 \mathrm{~km}^{2}$. The results using fuzzy logic-based GIS mapping show that $3.6 \mathrm{~km}^{2}$ of $9.69 \mathrm{~km}^{2}$ are at the high-risk zone to flooding regarding the existing population density and commercial areas prone to high flood damages of a given 100-year flood event or an extreme 500-year flood event, and $3.72 \mathrm{~km}^{2}$ areas are found exposed to the medium risk of flooding, which is much the same with high-risk zone exposed to flooding in the WLC method as shown in Tables 3 and 4 . Fuzzy and weighted linear combinations with Boolean logic methods are used to compare 100- and 500-year flood maps in Waverly City, respectively, and the results prove that fuzzy logic-based mapping evaluates the risk of floods better by combining flood hazard with caused damages in Waverly City within the $1000 \mathrm{~km}$ right and left of Cedar River. This study was successful in a relatively small area, while it may not be quite reliable in the case of larger areas. Therefore, for larger areas, hydraulic modeling and conventional WLC techniques can still be more reliable than fuzzy logic-based techniques used in this study.

The research shows that to make flood inundation models, many data such as topographic, bathymetric, hydraulic, and hydrologic are required, and it is not easy for anyone to collect all these data on time when facing an emergency; in addition, hydraulic models are analyzed after obtaining all these data and flood risk zones are created based on hydraulic model results with fuzzy logic-based GIS methodology to produce flood risk zones based only on accessible data such as topography and population density. Therefore, by applying this method to produce flood risk zones, an easy and trustful way for early and emergency decisionmaking and protection for flood risk can be possible. This method can provide the required information for the planned hydraulic flood models.

\section{Nomenclature}

$\begin{array}{ll}\text { GIS } & \text { Geographic Information System } \\ \mathrm{m} & \text { Meter } \\ \mathrm{km}^{2} & \text { Kilometer square } \\ \text { WLC } & \text { Weightage-based Linear Combination } \\ \text { HEC-SSP } & \begin{array}{l}\text { Hydrologic Engineering Center- } \\ \text { Statistical Software Package }\end{array} \\ \mathrm{MS} & \text { Membership small } \\ n & \text { Manning's coefficient } \\ \text { DEM } & \text { Digital Elevation Model } \\ \text { FR } & \text { Flood Risk } \\ P & \text { Probability of flood occurrence } \\ D & \text { Damage } \\ \text { FEMA } & \text { Federal Emergency Management } \\ & \text { Agency }\end{array}$

\section{References}

1. Alderman, K., Turner, L.R., and Tong, S. "Floods and human health", A Systematic Review. Environ. Int., 47, pp. 37-47 (2012).

2. Al-Hanbali, A., Alsaaideh, B., and Kondoh, A. "Using GIS-based weighted linear combination analysis and remote sensing techniques to select optimum solid waste disposal sites within Mafraq City", Jordan. J. Geogr. Inform. Syst, 3(4), pp. 267-278 (2011).

3. Phong, T., Rajib, S., Guillaume, C., and Norton, J. "GIS and local knowledge in disaster management: a case study of flood risk mapping in Viet Nam", Disasters, 33(1), pp. 152-169 (2009).

4. Chang, H. and Franczyk, J. "Climate change, land-use change and floods: Toward an integrated assessment", Geogr. Compass, 5(2), pp. 1549-1579 (2008).

5. Aydi, A., Zairi, M., and Dhia, B.H. "Minimization of environmental risk of landfill site using fuzzy logic, analytical hierarchy process and weighted linear combination methodology in a geographic information system environment", Environ. Earth Sci., 68(5), pp. 1375-1389 (2012).

6. Camarasa B.A.M., López-García, M.J., and SorianoGarcía, J. "Mapping temporally-variable exposure to flooding in small Mediterranean basins using land-use indicators", Appl. Geogr., 31(1), pp. 136-145 (2011).

7. Malczewski, J., GIS and Multicriteria Decision Analysis, John Wiley and Son, Toronto (1999). 
8. Mirzapour Al-E-Hashem, S.M.J., Malekly, H., and Aryanezhad, M.B. "A multi-objective robust optimization model for multi-product multi-site aggregate production planning in a supply chain under uncertainty", Int. J. Prod. Econ., 134(1), pp. 28-42 (2011).

9. Mohd, M.S., Alias, B., and Daud, D. "GIS analysis for flood hazard mapping: Case study; Segamat, Johor, West Malaysia", Proceeding of National Seminar on Geographic Information System Application for Mitigation in Natural Disaster, pp. 1-15 (2006).

10. Itami, R. and Cotter, M. "Application of analytical hierarchy process to rank issues, projects and sites in integrated catchment management", In Proc. the 2nd International Conference on Multiple Objective Decision Support Systems for Land, Water and Environmental Management, Queensland Department of Natural Resources and Mines, Brisbane, Australia (2012).

11. Tao, Z.H. and Jingdong, W. "Application of analytic hierarchy process in debris flow risk degree assessment - a case study of Miyun County, Beijing City", Bulletin of Soil and Water Conservation, 28(5), pp. 6-10 (2008).

12. Lawal, D., Matori, A., Hashim, A., Yusof, K., and Chandio, I. "Detecting flood susceptible areas using GIS-based analytic hierarchy process", In Proc. International Conference on Future Environment and Energy, 28, pp. 3-4 (2015).

13. Federal Emergency Management Agency, 2015/http:// www.fema.gov/flood-zone

14. Chaochao, L. and Xiaotao, C. "A frame work for flood risk analysis and benefit assessment of flood control measures in urban areas", Int. J. of River Basin Management, 13, pp. 13-15 (2016).

15. Brito, M. and Evers, M. "Multi-criteria decisionmaking for flood risk management: a survey of the current state of the art", Supplement of Natural Hazard Earth System, 16, pp. 1029-1033 (2016).
16. Das, E. "An aggregate fuzzy risk analysis for flood incident management", Int. J. of System Assurance Engineering and Management, 24, pp. 87-93 (2011).

17. Kourgialas, K. "Flood management and a GIS modeling method to assess flood-hazard areas", Hydrological Sciences Journal, 11, pp. 123-132 (2016).

18. Li E. "Impact assessment of urbanization on flood risk in the Yangtze River Delta", Stochastic Environmental Research and Risk Assessment, 27, pp. 25-37 (2016).

19. Sönmez, O. " $2 \mathrm{D}$ Flood Modelling and Flood map production in Rivers", Sakarya University, Institute of Applied Sciences, Sakarya., pp. 60-80, Sakarya, Turkey (2013).

\section{Biographies}

Osman Sönmez is an Assistant Professor at Sakarya University. He has graduated with Master's degree and PhD from Sakarya University in 2008 and 2013, respectively, and went on as a visiting scholar at the University of Iowa from 2012 to 2013; since then, he has published many works in different fields such as flood management and control and had been involved in numerous projects from the Turkish government research institution (TÜBITAK).

Hussein Bizimana is currently a $\mathrm{PhD}$ Student at Istanbul Technical University in Hydraulic and Water resources Engineering program, Civil Engineering Department. He was born on 1 July 1988 in Kigali Rwanda. He studied Civil Engineering and Environmental technology at Kigali Institute of Science and Technology, the University of Rwanda, Science and Technology College. In 2013, he joined Sakarya University in Civil Engineering for masters studies in Hydraulics Engineering and graduated from Sakarya University in July 2016. He has published 2 papers of international standards. 